P.N. Malani

J.J. Bleicher

C.A. Kauffman

D.S. Davenport

Key words:

dactylaria; dematiaceous fungi;

phaeohyphomycosis; renal transplant

Received 12 October 1999, revised 21 January, accepted for publication 25 January 2000

Copyright $\odot$ Munksgaard 2001

Transplant Infectious Disease . ISSN 1398-2273

Transpl Infect Dis 2001: 3: 40-43

Printed in Denmark . All rights reserved

\title{
Disseminated Dactylaria constricta infection in a renal transplant recipient
}

Abstract: We report the case of a 32-year-old renal transplant recipient who developed disseminated Dactylaria constricta infection. The patient died despite treatment with amphotericin B, itraconazole, and fluconazole.

Dactylaria constricta is a brown-black fungus found in soil and decaying vegetation. This dematiaceous fungus causes encephalitis and brain abscesses in several different types of birds, and recently has been noted to cause infection in humans $(1,2)$. All reported cases have occurred in immunocompromised patients, the majority being transplant recipients (3-10). Diagnosis may be difficult, and treatment remains problematic. We report a case of disseminated $D$. constricta infection in a 32-year-old renal transplant recipient and review the English-language literature encompassing infection with this organism in immunocompromised hosts.

\section{Case report}

A 32-year-old man who had received a cadaveric renal transplant for diabetic nephropathy 6 months previously presented to hospital with right-sided pleuritic chest pain in December 1993. He had experienced two episodes of rejection in the early post-transplant period, for which he had received OKT3 and pulse methylprednisolone treatment. Renal function had not normalized. The patient's immunosuppressive regimen at the time of admission consisted of prednisone and azathioprine. Physical examination revealed a well nourished man in no distress with a temperature of $97.5^{\circ} \mathrm{F}$, pulse of 80 beats/min, respirations of 20/min, and blood pressure of 115/75

\author{
Authors' affiliations: \\ P.N. Malani ${ }^{1}$, \\ J.J. Bleicher ${ }^{2}$ \\ C.A. Kauffman ${ }^{1}$, \\ D.S. Davenport ${ }^{2}$ \\ ${ }^{1}$ Division of Infectious \\ Diseases, Department of \\ Internal Medicine, Veterans \\ Affairs Healthcare System, \\ University of Michigan \\ Medical School, Ann Arbor, \\ Michigan, USA, \\ ${ }^{2}$ Division of Infectious \\ Diseases, Department of \\ Internal Medicine, \\ Kalamazoo Center for \\ Medical Studies, Michigan \\ State University School of \\ Human Medicine, \\ Kalamazoo, Michigan, USA \\ Correspondence to: \\ Carol A. Kauffman, M.D. \\ VA Healthcare System \\ 2115 Fuller Road \\ Ann Arbor, MI 48105 \\ USA \\ Tel: +7347617984 \\ Fax: +7347697039 \\ e-mail: ckauff@umich.edu
}




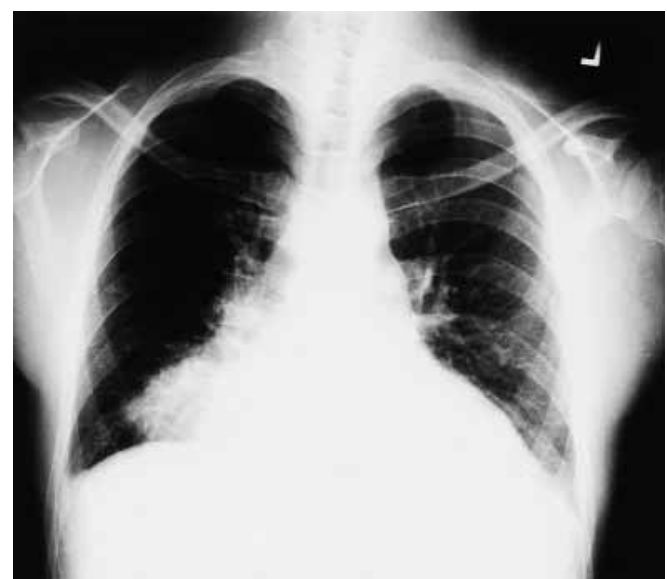

Fig. 1. Chest radiograph demonstrating a right middle lobe infiltrate and a small pleural effusion.

mmHg. Rhonchi were heard at the right lung base. The examination was otherwise within normal limits.

His white blood cell (WBC) count was $800 / \mu \mathrm{L}$, with $12 \%$ neutrophils, hemoglobin was $7.3 \mathrm{~g} / \mathrm{dL}$, and platelets were $35,000 / \mu \mathrm{L}$. Creatinine was $2.9 \mathrm{mg} / \mathrm{dL}$ and blood urea nitrogen (BUN) was $83 \mathrm{mg} /$ dL. A chest radiograph demonstrated a right middle lobe infiltrate with possible involvement of the superior segment of the right lower lobe. Bronchoscopy revealed moderate edema of the right middle lobe bronchus; bronchial washings were negative for cytomegalovirus and other viruses, mycobacteria, mycoplasma, chlamydia, and Pneumocystis. Culture yielded sparse growth of alpha-hemolytic streptococci, Candida albicans, and coagulase-negative staphylococci. The patient received erythromycin for presumed communityacquired pneumonia. Azathioprine was replaced with FK506 (tacrolimus), which was obtained on an experimental protocol. Although the patient improved clinically on erythromycin therapy and was discharged home, his chest radiograph showed a persistent right middle lobe infiltrate.

Three months later the patient again developed right-sided chest pain and cough. He was taking FK506 per protocol and prednisone $30 \mathrm{mg}$ daily. Physical examination revealed a temperature of $96.8^{\circ} \mathrm{F}$, a pulse of 78 beats/min, respirations of $24 / \mathrm{min}$, and blood pressure of 110/80 mmHg. Breath sounds were diminished at the right base. The right upper quadrant was tender to palpation. Laboratory results showed a WBC of $16,800 / \mu \mathrm{L}$, creatinine of $3.9 \mathrm{mg} / \mathrm{dL}$, BUN of $102 \mathrm{mg} / \mathrm{dL}$, and blood glucose of $332 \mathrm{mg} / \mathrm{dL}$. Oxygen saturation was $95 \%$ on $2 \mathrm{~L}$ of oxygen. A chest radiograph demonstrated a right middle lobe infiltrate and a small pleural effusion (Fig. 1).

Intravenous ceftriaxone and erythromycin were given. Tacrolimus was continued, and $100 \mathrm{mg}$ of intravenous hydrocortisone were given every 6 h. Sputum cultures yielded only C. albicans and normal respiratory flora. Bronchoscopy done on hospital day 8 revealed mucopurulent secretions and a narrowing at the right middle lobe bronchus. Cultures yielded Candida species and a brown filamentous mould, later identified as $D$. constricta. The physician caring for the patient thought that he might have Candida pneumonia, discontinued the antibiotics, and began intravenous fluconazole, 100 mg daily. The mould was thought to be a contaminant. However, the patient's condition deteriorated and he required increased oxygen support. Fluconazole was stopped and intravenous amphotericin B, $0.5 \mathrm{mg} / \mathrm{kg} /$ day, was initiated on hospital day 12 .

Continued hypoxemia prompted intubation and an open lung biopsy on hospital day 24, which demonstrated acute inflammation and extensive necrosis. Hematoxylin and eosin stain revealed numerous golden-brown hyphae. On Gomori methenamine silver stain, the organisms were noted to have branching, septate mycelial processes and round yeast-like forms. Culture of the biopsy material yielded $D$. constricta.

The amphotericin B dose was increased to $1.0 \mathrm{mg} / \mathrm{kg}$ daily, and oral itraconazole, $600 \mathrm{mg}$ daily, was added. The tacrolimus was tapered off and the corticosteroids were decreased over the next few days. After 5 days, intraconazole was changed to intravenous fluconazole because the patient's pulmonary status was deteriorating and he was unable to take the oral formulation of itraconazole. His mental status declined, and a noncontrast-enhanced computerized tomography (CT) examination of the brain revealed multiple low-attenuation lesions. Given the patient's grave prognosis, aggressive therapy was withdrawn, and he died on hospital day 32.

Autopsy revealed extensive consolidation of the entire right lung and the upper lobe of the left lung, with cavity formation in the

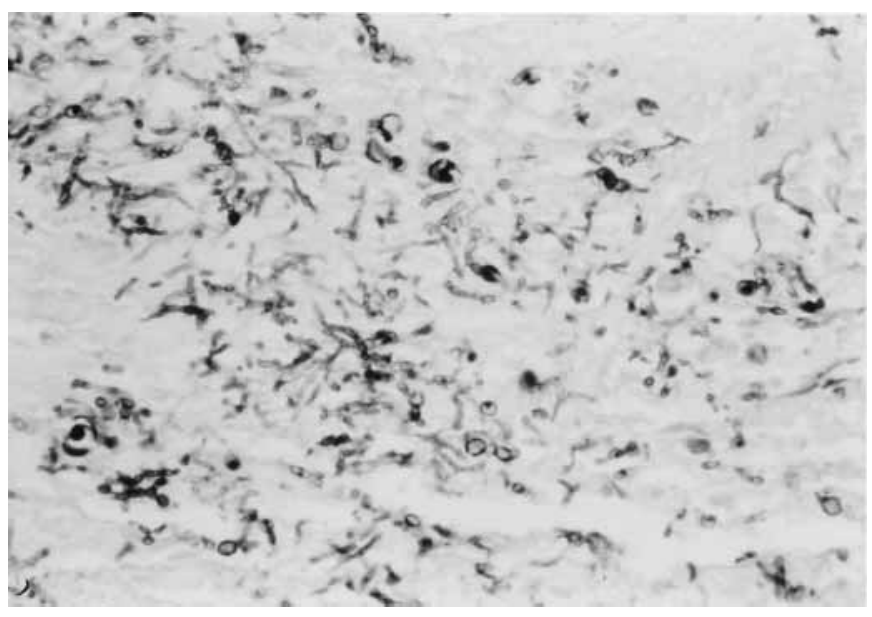

Fig. 2. Lung tissue stained by Gomori methenamine silver stain demonstrating necrosis with numerous septate hyphae and thickwalled globose structures, which were light brown on hematoxylin and eosin stain. 
Reported cases of Dactylaria infection in humans

\begin{tabular}{|c|c|c|c|c|c|c|}
\hline Ref. & $\begin{array}{l}\text { Age, } \\
\text { Sex }\end{array}$ & Underlying conditions & Organ involvement & Method of diagnosis & Antifungal therapy & Outcome \\
\hline 3 & $58 / F$ & Acute myeloblastic leukemia & Skin & Skin biopsy & $5 \mathrm{FC}$ & Cured \\
\hline 4 & $62 / \mathrm{M}$ & T-cell leukemia, IDDM & $\begin{array}{l}\text { Brain, lung, liver, } \\
\text { spleen, kidney }\end{array}$ & Autopsy & None & Died \\
\hline 5 & $60 / M$ & $\begin{array}{l}\text { Large cell lymphoma, Nocardia asteroides } \\
\text { pulmonary infection }\end{array}$ & Brain & Excision, brain abscess & $\begin{array}{l}\text { AmB } 0.5 \mathrm{mg} / \mathrm{kg} / \text { day, } \\
5 \mathrm{FC} 150 \mathrm{mg} / \mathrm{kg} / \text { day, } \\
\text { Flu (dose not noted) }\end{array}$ & Died \\
\hline 6 & $30 / \mathrm{M}$ & Heart transplant & Lung & Lung biopsy & $\mathrm{AmB}, 811 \mathrm{mg}$ & Cured \\
\hline 7 & $68 / M$ & Liver transplant, cryptogenic cirrhosis & Brain & Aspiration, brain abscess & $\begin{array}{l}\text { AmB, } 200 \mathrm{mg}, \mathrm{ABCD}, 8.5 \mathrm{~g}, \\
5 \mathrm{FC} \times 4 \text { weeks. } \\
\text { Itra } 200 \mathrm{mg} / \text { day } \times 1 \text { year }\end{array}$ & Cured \\
\hline 8 & $63 / M$ & Liver transplant, alcoholic cirrhosis, IDDM & Brain & Aspiration, brain abscess & $A m B \times 10$ days, Itra $\times 3$ days & Died \\
\hline 9 & $59 / M$ & $\begin{array}{l}\text { Liver transplant, cryptogenic cirrhosis, } \\
\text { Nocardia asteroides pulmonary infection }\end{array}$ & Brain & Aspiration, brain abscess & $\mathrm{AmB}, 2.5 \mathrm{~g}$ & Died \\
\hline 10 & $58 / \mathrm{M}$ & Heart transplant, IDDM & Lung & Lung biopsy & $\begin{array}{l}\text { Itra } 400 \mathrm{mg} / \text { day } \times 15 \text { weeks, } \\
\text { AmB } 400 \mathrm{mg}\end{array}$ & Cured \\
\hline $\begin{array}{l}\text { Present } \\
\text { case }\end{array}$ & $32 / M$ & Renal transplant, IDDM & Lung, brain, thyroid & Lung biopsy & $\begin{array}{l}\text { Flu } 100-400 \text { mg/day, } \\
\text { AmB } 0.5-1.0 \mathrm{mg} / \mathrm{kg} / \text { day, } \\
\text { Itra } 600 \mathrm{mg} / \text { day }\end{array}$ & Died \\
\hline
\end{tabular}

Table 1.

right lower lobe, and widespread necrosis of perihilar and paratracheal lymph nodes. Multiple black, necrotic lesions were seen in the cerebellum, the periventricular white matter, and the thyroid gland. Microscopic examination demonstrated extensive necrosis with neutrophils and multi-nucleated giant cells, as well as numerous goldenbrown pigmented, septate hyphae and thick-walled globose structures (Fig. 2). Susceptibility studies (performed by Dr. M. Rinaldi at the University of Texas Health Science Center at San Antonio) revealed minimum inhibitory concentrations (MIC) as follows: amphotericin $\mathrm{B}, 0.5 \mu \mathrm{g} / \mathrm{mL}$; flucytosine, $0.5 \mu \mathrm{g} / \mathrm{mL}$; fluconazole, $32 \mu \mathrm{g} / \mathrm{mL}$; itraconazole, $0.06 \mu \mathrm{g} / \mathrm{mL}$.

\section{Discussion}

D. constricta is a thermotolerant, dematiaceous fungus that has been isolated from ecological niches as diverse as effluents of nuclear power plants, thermal springs, decaying vegetation, and chicken litter $(1,2,8)$. This organism is able to grow at temperatures as high as $45^{\circ}$ C. D. constricta was first described in 1964 as the etiologic agent of epidemic encephalitis in turkey poults in South Carolina (11). Since that first description under the name Diplorhinotrichum gallopavum, the organism has undergone several taxonomic changes. Currently, the designation $D$. constricta encompasses two previously described organisms, Ochroconis gallopavum and Scolecobasidium constrictum $(2,6,8)$.

During the past decade Dactylaria species have been increasingly reported as a cause of infection in immunosuppressed humans (Table 1). While the paucity of cases and the brief descriptions of several of these case histories makes it difficult to form generalizations regarding the presentation and clinical course, certain descriptive data can be gleaned from earlier reports. Eight of the 9 patients were men, and ages ranged from 30 to 63 years. Our patient is the sixth transplant recipient reported to have had $D$. constricta infection (6-10); there were 3 liver transplant and 2 heart transplant recipients prior to this report. Three other patients had hematologic malignancies (3-5). Four patients had insulin-dependent diabetes mellitus. Several patients had possible exposure to the organism through vocational or recreational activities involving soil (6-8), and 2 patients had infection with Nocardia asteroides, another soil organism, documented 2 months and 2 years prior to infection with Dactylaria, respectively $(5,9)$. Most patients, including ours, however, had no obvious exposure to Dactylaria.

The pulmonary lesions in our patient and the others previously reported were similar to those noted with infection with other filamentous fungi, such as Aspergillus. The infiltrates were usually nodular, and cavity formation was common. A combination of granulomatous inflammation and necrosis was typically noted on histopathological examination $(4,6,10)$. 
The neurotropic predilection of $D$. constricta has been previously commented on (11-15), and is demonstrated by the cases in this review; 6 of the 9 patients had brain abscesses. CT scans in most revealed multiple ring-enhancing lesions. An experimental murine model has defined the pathogenesis of the cerebral lesions following hematogenous spread to the central nervous system (13).

In transplant recipients, a more typical presentation of infection due to other dematiaceous fungi, such as Exophiala and Phialophora, is that of skin and subcutaneous nodular lesions (15, 16). These other dematiaceous fungal infections are predominantly acquired by direct inoculation, tend to be indolent for weeks to months, and are unlikely to disseminate (15). Only the patient described by Fukushiro et al. showed this type of illness with $D$. constricta (3).

There is no consensus regarding the appropriate treatment for Dactylaria infections. With the exception of one patient with subcutaneous abscesses who received only flucytosine (3), all patients who have been successfully treated received amphotericin B alone or in combination with itraconazole $(6,7,10)$. Amphotericin B would appear to be appropriate initial therapy for suspected Dactylaria infection, especially given the high percentage of cases with central ner- vous system (CNS) involvement. While itraconazole is recommended for treatment of phaeohyphomycotic infection due to dematiaceous fungi (16), poor penetration into the CNS and problematic absorption of the capsule formulation make this agent less attractive for treatment of infections due to Dactylaria.

Few case reports have documented susceptibility studies of $D$. constricta to antifungal agents $(7,8,10)$. In general, the organism is susceptible to amphotericin $\mathrm{B}$ and itraconazole and resistant to fluconazole and flucytosine. Fungal susceptibility studies are not standardized for filamentous fungi, but suggested methods have been published recently (17). Although the usefulness of susceptibility studies is debated, the MIC results for Dactylaria isolates from a reference laboratory are probably useful to help guide long-term therapy if the patient survives the acute infection.

Clinicians should be aware of D. constricta as a pigmented fungus that causes infection in transplant recipients. As demonstrated in this and previous reports, D. constricta has the potential to cause fatal illness, often with CNS involvement. Brown-black moulds isolated in culture should not be dismissed as contaminants; further microbiological follow-up is imperative and early aggressive antifungal therapy is essential.

\section{References}

1. Dixon DM, Polak-Wyss A. The medically important dematiaceous fungi and their identification. Mycoses 1991: 34: 1-18.

2. Dixon DM, SAlkin IF. Morphologic and physiologic studies of three dematiaceous pathogens. J Clin Microbiol 1986: 24: 250259.

3. FukUshiro R, Udagawa S, Kawashima Y, KaWAmURA Y. Subcutaneous abscesses caused by Ochroconis gallopavum. J Med Vet Mycol 1986: 24: 175-182.

4. Terreni AA, Disalvo AF, Baker AS, Crymes WB, Morris PR, DOWdA H. Disseminated Dactylaria gallopava infection in a diabetic patient with chronic lymphocytic leukemia of the T-cell type. Am J Clin Pathol 1990: 94: 104-107.

5. Sides EH, Benson JD, Padhye AA. Phaeohyphomycotic brain abscess due to Ochroconis gallopavum in a patient with malignant lymphoma of a large cell type. J Med Vet Mycol 1991: 29: 317-322.

6. Mancini MC, McGinnis MR. Dactylaria infection of a human being: pulmonary disease in a heart transplant recipient. J Heart Lung Transpl 1992: 11: 827-830.
7. VuKMir RB, Kusne S, Linden $\mathrm{P}$, et al. Successful therapy for cerebral phaeohyphomycosis due to Dactylaria gallopava in a liver transplant recipient. Clin Infect Dis 1994: 19: 714-719.

8. Kralovic SM, Rhodes JC. Phaeohyphomycosis caused by Dactylaria (human dactylariosis): Report of a case with review of the literature. J Infection 1995: 31: 107-113.

9. Rossmann SN, Cernoch PL, Davis JR. Dematiaceous fungi are an increasing cause of human disease. Clin Infect Dis 1996: 22: 73-80.

10. Jenney A, Maslen M, Bergen P, Tang S, Esmore D, Fuller A. Pulmonary infection due to Ochroconis gallopavum treated successfully after orthotopic heart transplant. Clin Infect Dis 1998: 26: 236-237.

11. Georg LK, Bierer B, CoOKe WB. Encephalitis in turkey poults due to a new fungus species. Sabouraudia 1964: 3: 239244.

12. Dixon DM, Walsh TJ, Salkin IF, Polak A. Dactylaria constricta: another dematiaceous fungus with neurotropic potential in mammals. J Med Vet Mycol 1987: 25: 55-58.
13. Walsh TJ, Dixon DM, Polak A, Salkin IF. Comparative histopathology of Dactylaria constricta, Fonsecaea pedrosoi, Wangiella dermatitidis, and Xylohypha bantiana in experimental phaeohyphomycosis of the central nervous system. Mykosen 1987: 30: 215-225.

14. Dixon DM, PolaK A. In vitro and in vivo drug studies with three agents of central nervous system phaeohyphomycosis. Chemotherapy 1987: 33: 129-140.

15. Singh N, Chang FY, Gayowsis T, Marino IR. Infections due to dematiaceous fungi in organ transplant recipients: Case report and review. Clin Infect Dis 1997: 24: 369374.

16. Sharkey PK, Graybill JR, RinAldi MG, et al. Itraconazole treatment of phaeohyphomycosis. J Am Acad Dermatol 1990: 23: 577-586.

17. Espinel-Ingroff A, Bartlett M, Bowden $\mathrm{R}$, et al. Multicenter evaluation of proposed standardized procedure for antifungal susceptibility testing of filamentous fungi. J Clin Microbiol 1997: 35: 139-143. 